\title{
THE NON-SPECIFICITY OF THE INTRATHECAL REACTION TO TUBERCULIN IN MULTIPLE SCLEROSIS
}

\author{
BY \\ JOHN MARSHALL and FRANCIS O'GRADY

\begin{abstract}
From the Academic Unit, Institute of Neurology and National Hospitals for Nervous Diseases, Queen Square, and the Bland-Sutton Institute of Pathology, Middlesex Hospital, London
\end{abstract}

The intrathecal injection of the purified protein derivative of tuberculin (P.P.D.) was used by Smith, Vollum, Taylor, and Taylor (1956) in the treatment of tuberculous meningitis. They had been led to use this method by the observation that the cellular and protein content of the cerebrospinal fluid of patients with tuberculous meningitis showed marked fluctuations which they believed to be due to the liberation of tubercular protein into the sensitized meninges. The presence of these fluctuations was associated with clinical improvement; hence they wondered whether this effect could be reproduced by the intrathecal injection of tuberculin. Considerable success was achieved with this method of treatment.

The injection of P.P.D. in patients with tuberculous meningitis produced a characteristic disturbance of the cellular and protein content of the cerebrospinal fluid. This consisted of a brisk outpouring of predominantly polymorphonuclear cells within the first 24 hours accompanied by a similar rise in protein. This was followed by a wave of mononuclear cells maximal between the third and seventh days after injection, there again being an accompanying rise in protein. A similar reaction, though often of less degree, was observed in a group of Mantoux-positive psychotic patients (Swithinbank, Smith, and Vollum, 1953). A further feature was that there appeared to be a correlation between the sensitivity of the meninges and that of the skin to tuberculin. In patients who were Mantouxnegative only a minimal disturbance was produced in the cerebrospinal fluid by the intrathecal injection of P.P.D., but the typical pattern of response could be obtained after successful vaccination of the patient with B.C.G. or vole bacillus.

More recently it has been found that in patients with multiple sclerosis the pattern of response is different from that seen in psychotics (Smith, Espir, Whitty, and Russell, 1957). These authors observed that the initial 24-hour spike of cells was absent, but the subsequent wave of mononuclear cells was well developed; in addition there was a biphasic rise in protein. The authors comment that there was a tendency for the protein rise to outstrip that of the cells. They observed no correlation between the sensitivity of the skin and that of the meninges in these patients. A similar type of reaction could be obtained in highly sensitive psychotic patients in whom the intrathecal injection of P.P.D. was covered by a small dose of cortisone. They interpreted these findings as indicating that the normal immunological processes are disordered in multiple sclerosis. They further suggested that the intrathecal injection of P.P.D. might have beneficial therapeutic effects in this disease.

Since no other chronic neurological diseases had been treated in this way, and there was therefore no reason to believe that the changes described were specific to multiple sclerosis, it seemed possible that the therapeutic benefit might be obtained in other conditions. In addition the belief that the type of reaction obtained in multiple sclerosis reflected a specific immunological abnormality made it essential to establish whether similar changes occurred in other diseases. We have therefore offered this treatment to patients with other incurable neurological diseases.

\section{Material and Methods}

Seventeen patients with multiple sclerosis, nine with motor neurone disease, three with Huntington's chorea without dementia, and three with Parkinsonism, all of whom were Mantoux-positive, have been treated. No patient was in the terminal stages of the disease. Their ages are shown in Table I.

In each case the first injection of P.P.D. was given on a Monday after removal of cerebrospinal fluid for examination. The cerebrospinal fluid was re-examined on Tuesday, Wednesday, and Friday. On the following Monday, if no clinical response had occurred, this procedure was repeated using a larger dose. The dose of P.P.D. used for each patient is set out in Table I. With increasing familiarity with the clinical response larger initial doses were employed. 
TABLE I

DETAILS OF CEREBROSPINAL FLUID RESPONSE IN THE PRESENT SERIES

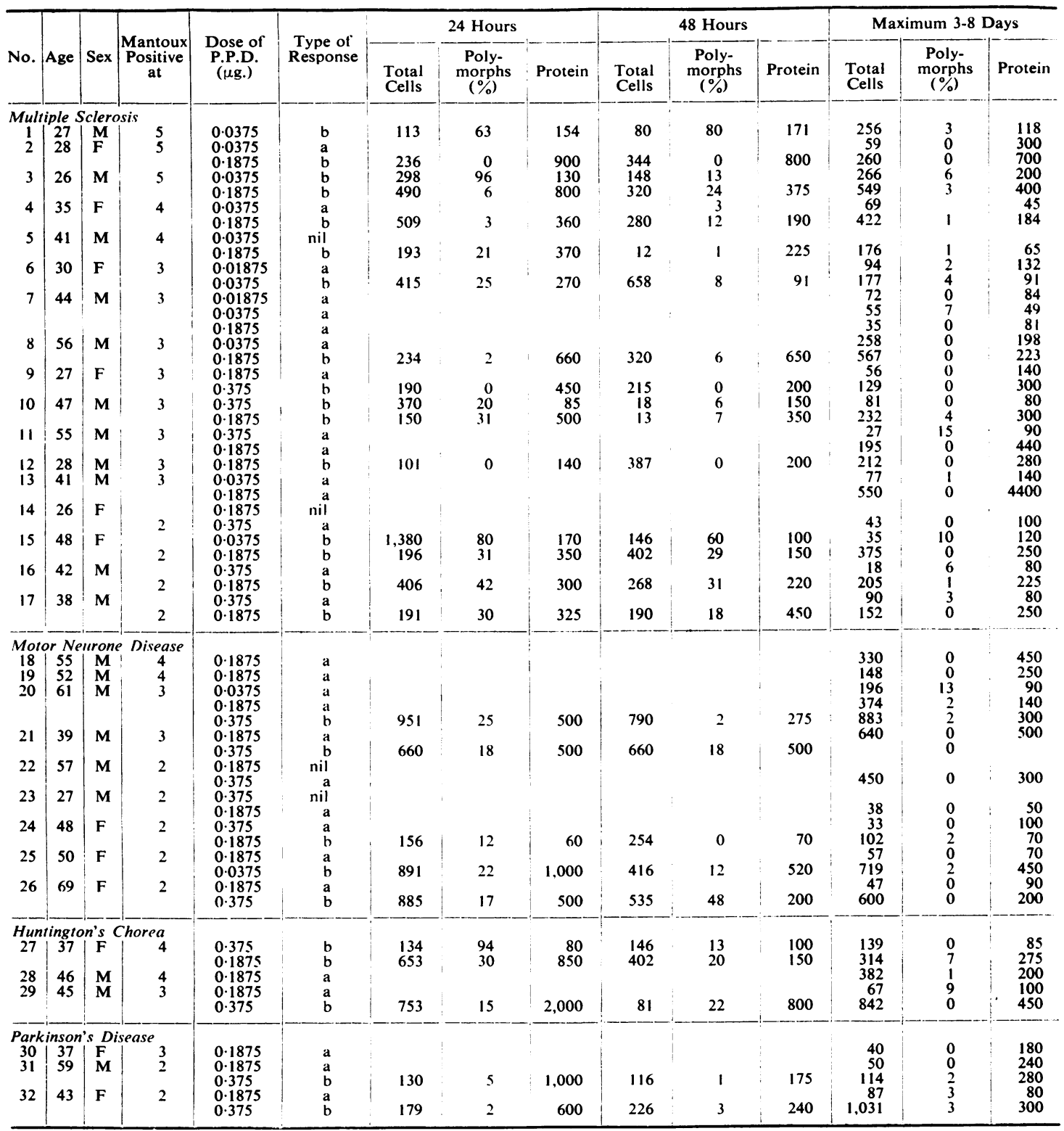

The Clinical Response.-This was characterized by headache, neck stiffness, fever, vomiting, and in many cases drowsiness. Patients who did not develop these symptoms were completely unaffected.

Examination of the Cerebrospinal Fluid.-Cell counts were performed in the Fuchs Rosenthal chamber and preparations of the centrifuged deposit stained by Leishman's method. All the examinations were made by one of us (F.O'G). Protein was estimated in the first 15 cases by a micro-Kjeldahl method. Subsequently a nephelometric method was employed and a correction was applied (J. Arthur, personal communication).

Skin Testing.-Doses of $10,1,0 \cdot 1$, and occasionally 0.01 tuberculin units (t.u.) were given on the day on which the first intrathecal injection of P.P.D. was made ( $1 \mathrm{t}$.u. is contained in $0.1 \mathrm{ml}$. of 1 in 10,000 dilution of 
tuberculin). Separate syringes were used for each dilution and separate needles for each patient. The injections were made in order on the anterior aspect of the forearm so that the greatest dilution was most distal. The areas of erythema and induration were measured daily and recorded as previously described (O'Grady, 1956). Patients who failed to respond were tested with $100 \mathrm{t} . \mathrm{u}$. at the time the second dose of intrathecal P.P.D. was given.

\section{Results}

Results in Multiple Sclerosis.-The intrathecal injection of the first dose of P.P.D. produced no response in the cerebrospinal fluid of two patients and a slow rise of cells in 10 of the 17 patients. This slow rise of cells was called the " $a$ " type response. The administration of a second dose one week after the first to one of the patients (Case 14) who had no cellular response produced an "a" type response in the cerebrospinal fluid accompanied by a clinical response; hence she was given no further P.P.D. Likewise two of the 10 patients (Cases 11 and 13) gave a second "a" type response, and one patient (Case 7) a third, accompanied by a clinical response, and they were given no more P.P.D. The second patient who had failed to respond to the first dose (Case 5) and the remaining seven of the 10 patients who had given an "a" response produced a different type of reaction to their second dose of P.P.D. This was characterized by a peak of cells maximal within 48 hours which subsequently settled to a plateau, or was followed by a further wave of cells maximal between the third and the seventh day. This latter type of response we have called the " $b$ " type. Five of the 17 patients gave only the " $b$ " type response. Three of these patients had two " $b$ " type responses, the first of which was not accompanied by a clinical reaction. In the "a" type response more than $90 \%$ of the cells were mononuclear, except in one case (Case 11) where $15 \%$ of polymorphs were found. Similarly, the predominant cell in the " $b$ " type response was again the mononuclear, and in nine of the 13 cases the percentage of polymorphs did not exceed 31. In the remaining four patients, two of whom gave two "b" type responses (Cases 3 and 15), the percentage of polymorphs in the first response was $63,96,80$, and 42 . Details of these responses are set out in Table 1.

During the " $a$ " type response the protein showed a slow rise maximal between three and seven days. Associated with the " $b$ " type response the protein showed a sharp peak within the first 48 hours followed by a plateau or a second less sharp increase. A typical combination of " $a$ " and " $b$ " type response is shown in Fig. 1. The frequency with which " $a$ " and "b" type responses were encountered are given in Table II. The maximum, minimum, and 4
TABLE II

FREQUENCY OF TYPE OF RESPONSE IN EACH NEUROLOGICAL DISEASE

\begin{tabular}{l|c|c|c|c}
\hline & $\begin{array}{c}\text { Multiple } \\
\text { Selerosis }\end{array}$ & $\begin{array}{c}\text { Motor } \\
\text { Neurone } \\
\text { Disease }\end{array}$ & $\begin{array}{c}\text { Parkinsonism } \\
\text { and } \\
\text { Huntington's } \\
\text { Chorea }\end{array}$ & Total \\
\hline "a" type only & 4 & 4 & 2 & 10 \\
"b" type only \\
"a" and "b" type & 6 & $\frac{5}{5}$ & 3 & 15 \\
\hline Total & 7 & 9 & 6 & 32 \\
\hline
\end{tabular}

mean cellular and protein responses during the " $a$ ", type responses are shown in Fig. 2, and in the "b" type response in Fig. 3.

Results in Other Conditions. - The results in the three other chronic neurological diseases which we have studied differed in no essential from those described above. Of the nine cases of motor neurone disease, four gave an "a" type response and five "a" plus " $b$ " type responses. The percentage of polymorphs did not exceed 13 in the "a" type responses and 50 in the "b" type responses. In the two other conditions, Huntington's chorea and Parkinsonism, two of the six patients gave an " $a$ ", type response, one a " $b$ " type, and three an " $a$ " plus " $b$ " type. The similarity between the results in the various conditions is shown in Figs. 1, 2, and 3.

Skin Sensitivity to Tuberculin.-Two patients who were suffering from Parkinsonism and proved to be Mantoux-negative are not included in the series. In one the injection of $0.1875 \mu \mathrm{g}$. and subsequently $0.375 \mu$ g. P.P.D. produced a minimal disturbance in cells and protein. In the other the injection of $0 \cdot 1875 \mu$ g. P.P.D. produced a maximum of 150 cells at 24 hours of which $50 \%$ were polymorphs with no change in protein. In the Mantoux-positive patients there was no direct correlation between the degree of skin sensitivity to tuberculin and the magnitude of the response in the cerebrospinal fluid (Table I).

\section{Discussion}

From the analysis of the temporal pattern of the responses in number and types of cells and the amount of protein, there appear to be two types of response in the present series. The first, which we have called the " $a$ " type response, is characterized by a slow steady rise in the levels of cells and protein. The second, " $b$ " type response, consists of a peak of cells and protein within the first 48 hours, followed by a plateau or second wave of cells and protein maximal between the third and seventh days. The type of cell does not appear to be a criterion by which the responses can be differentiated 


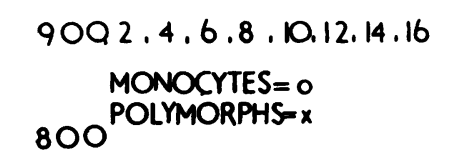

700

600

D S

$\underbrace{500}_{400}$

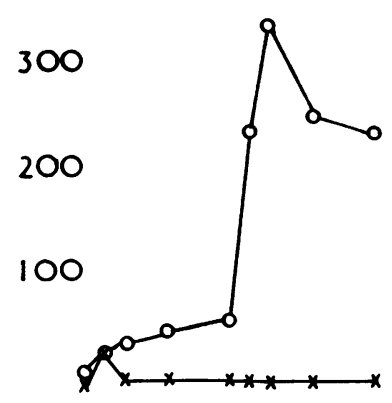

1000

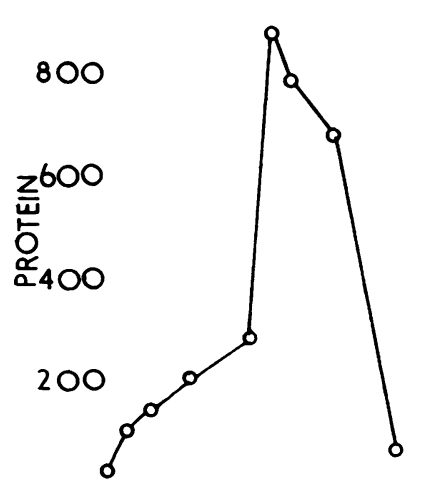

DAYS' $2^{\prime} 4^{\prime} 6^{\prime} 8^{\prime} 10^{\prime} 12^{\prime} 14^{\prime} 16$ PPD१

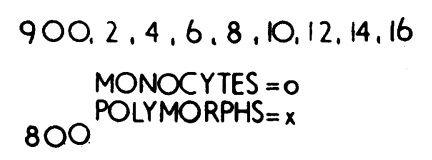

700

600

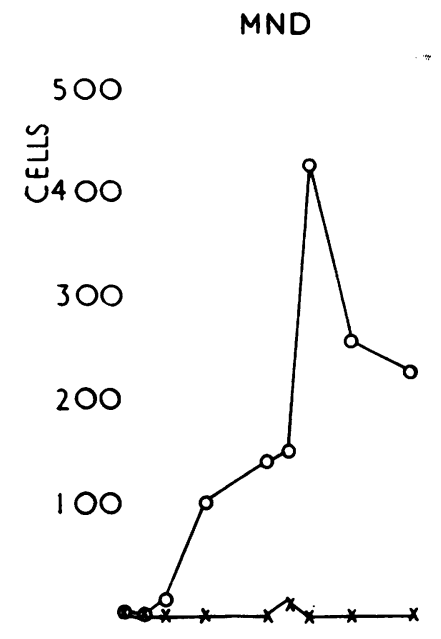

1000

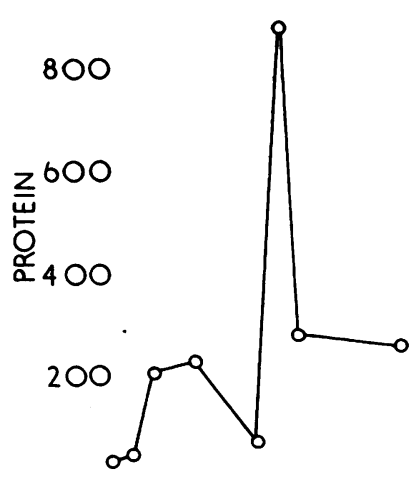

DAYS' $2^{\prime} 4^{\prime} 6^{\prime} 88^{\prime} 10^{\prime} 12^{\prime} 14^{\prime} 16$ PPD^
$900.2 \cdot 4,6,8,10,12,14,16$

MONOCYTES $=0$

800 POLYMORPHS $=x$

700

600

PARKINSONISM

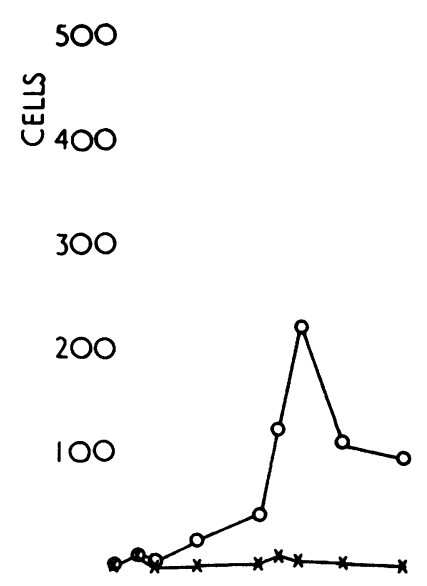

1000

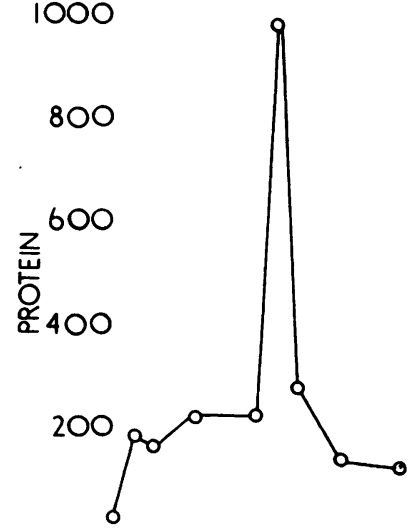

DAYS' $2^{\prime} 4^{\prime} 6^{\prime} 8^{\prime} 10^{\prime} 12^{\prime} 14^{\prime} 16$ PPD $\uparrow$

Fig. 1.-Typical examples of the "a" plus " $b$ " type responses in multiple sclerosis, motor neurone disease, and Parkinsonism. 

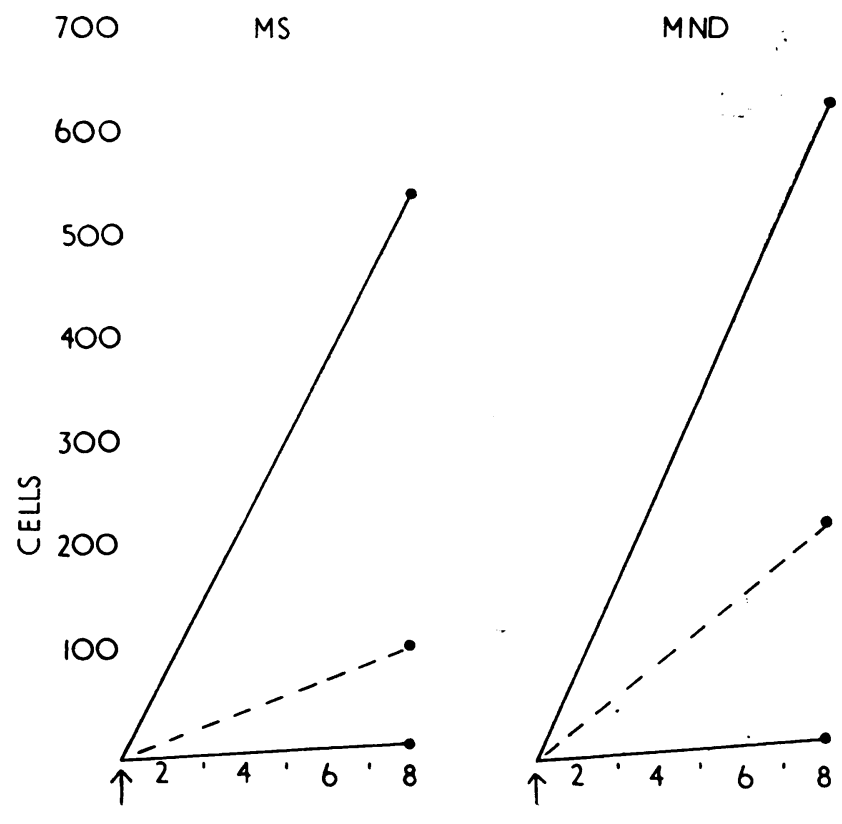

PARKINSONISM

HUNTINGTON'S

CHOREA
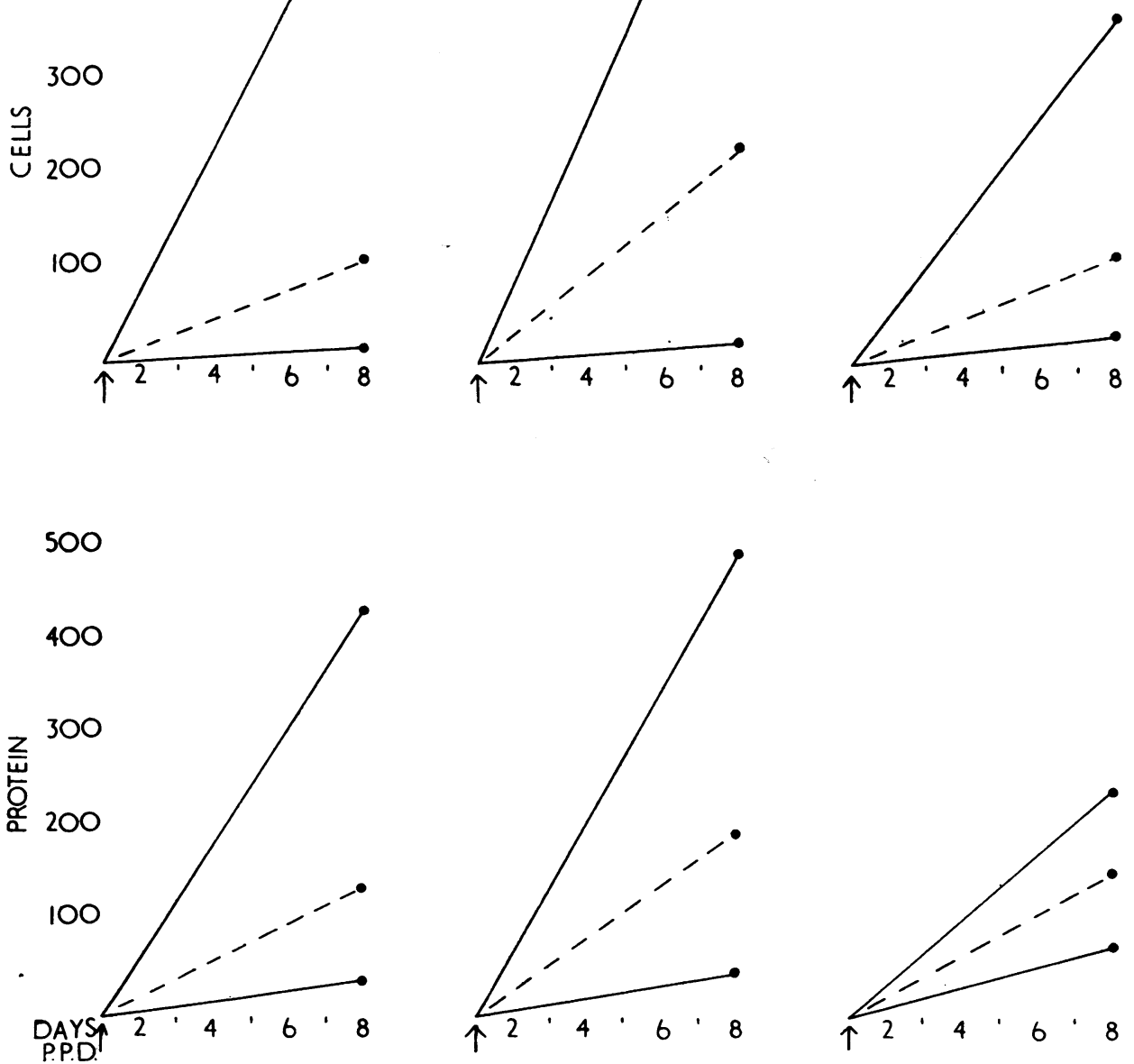

옹

FIG. 2.-A comparison of the maximum, minimum, and mean cells and protein in the "a" type response in the 17 patients with multiple sclerosis, nine with motor neurone disease, and six with Parkinsonism or Huntington's chorea. 


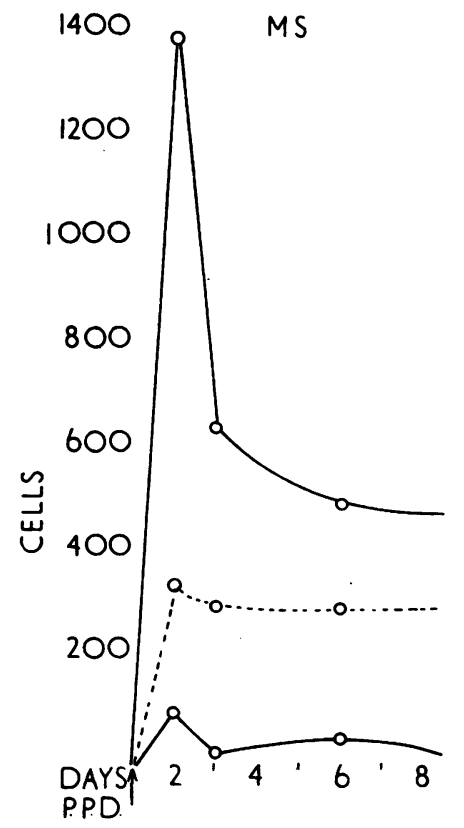

MND

PARKINSONISM

HUNTINCTON'S

CHOREA
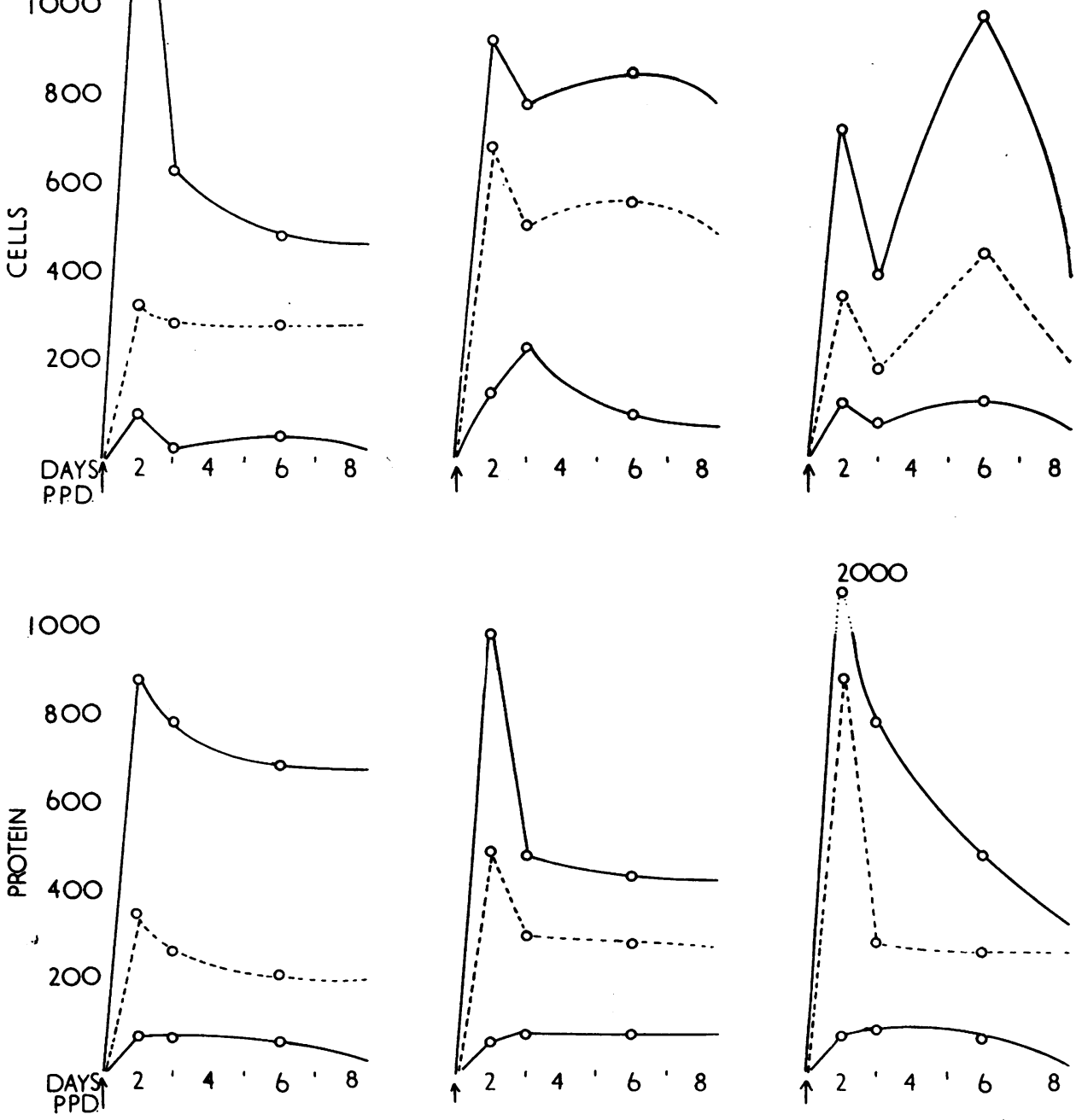

FIG. 3. -A comparison of the maximum, minimum, and mean cells and protein in the " $b$ " type response in the 17 patients with multiple sclerosis, nine with motor neurone disease, and six with Parkinsonism or Huntington's chorea. 
for the polymorphs ranged from 0 to $96 \%$ in a smooth continuum.

When the case material is examined according to the type of response there was no difference among the four chronic neurological diseases which were studied. Especially, the pattern found in multiple sclerosis differed in no essential feature from that found in the other three conditions. This result does not support the view of Smith et al. (1957) that the response in multiple sclerosis is specific to that condition.

We were concerned with the possibility that previous tuberculin testing might modify the response to intrathecal P.P.D. (O’Grady, 1957). Skin testing was therefore carried out simultaneously with the first intrathecal injection. Despite the fact that Smith et al. were treating patients who had presumably been skin tested previously, the pattern of response obtained in our patients was identical with theirs. Although they do not draw attention to the type of responses we have labelled the " $a$ " type response, their Fig., 2 M.D. and M.B., show typical "a" plus " $b$ " type responses.

We ha e therefore confirmed that the type of response obtained in multiple sclerosis is as they describe, but it is not specific to this condition as it is shared by the three other chronic neurological conditions which we have studied. We are left with the fact that all these neurological diseases give a pattern of response which is different from that found in tuberculous meningitis and from 13 reactions observed in psychotic patients. A direct comparison between the reactions in psychotic patients and in the Oxford cases of multiple sclerosis (Smith et al., 1957) is difficult for two reasons. First, the authors do not define what they regarded as the definitive response in the patients with multiple sclerosis. For example, Case 10 B.P. developed three cells at 24 hours and five as the peak after three to eight days. Secondly, all the psychotics were tested with $3.75 \mu$ g. P.P.D. whereas the patients with multiple sclerosis received a wide variety of doses. The Oxford workers have themselves (Swithinbank et al., 1953) previously drawn attention to the fact that the type of response obtained is greatly influenced by the dose of P.P.D. It is only possible therefore to compare the psychotics directly with the six patients with multiple sclerosis who received 3.75 $\mu$ g. P.P.D. Smith et al. say that the response in multiple sclerosis differs from that in psychotics in the absence of the initial spike of cells, the complete or partial suppression of the polymorphonuclear component, and in the tendency for the protein rise to outstrip and outlast the cellular response. A comparison of the cases of multiple sclerosis tested with $3.75 \mu \mathrm{g}$. with the psychotics (Table III) shows that the total cellular response was generally substantially greater at 24 hours in the psychotics $(P<0.01)$ and slightly greater at three to eight days. The percentage of polymorphs at 24 hours (Swithinbank et al., 1953) in psychotics fell between 35 and 94 . In the six cases of multiple sclerosis the percentages of polymorphs were $0,4,10,29,38$, and 84 . The difference of the means was again significant at the $1 \%$ level. Comparing the other chronic neurological diseases with the psychotics also shows a significant difference at the $1 \%$ level in the initial cell count and percentage of polymorphs present. A possible fallacy in the estimation of the percentage of polymorphs is that it is not uncommon for cells, which cannot be identified with confidence, to appear at the height of the response. Many of these cells are already damaged when examined immediately after lumbar puncture and are not identifiable even after specific staining. The allocation of these cells to their appropriate group is extremely difficult, and they may be present in such numbers as to influence

TABLE III

COMPARISON OF CEREBROSPINAL FLUID CHANGES IN PRESENT SERIES WITH PSYCHOTICS* AND MULTIPLE SCLEROSIS (OXFORD SERIES) $\dagger$

\begin{tabular}{|c|c|c|c|c|c|c|}
\hline & \multicolumn{3}{|c|}{24 Hours } & \multicolumn{3}{|c|}{ Three to Eight Days } \\
\hline . & Cells & $\underset{(\%)}{\text { Polymorphs }}$ & Protein & Cells & $\underset{(\%)}{\text { Polymorphs }}$ & Protein \\
\hline $\begin{array}{l}\text { Psychotics (13 reactions) } \\
\text { Multiple sclerosis (Oxford series) } \\
6 \text { patients } \\
\text { Multiple szlerosis (present series) } \\
\text { Motor neurone disease (present series) } \\
\text { Other diseases (present series) }\end{array}$ & $\begin{array}{l}520-4.560 \\
(2559) \\
30-620 \\
(214) \\
101-1,380 \\
(342) \\
156-957 \\
(710) \\
130-753 \\
(370)\end{array}$ & $\begin{array}{r}35-94 \\
0-84 \\
0-96 \\
12-25 \\
2-94\end{array}$ & $\begin{array}{l}90-600 \\
(296) \\
90-1,000 \\
(489) \\
85-900 \\
(373) \\
60-1,000 \\
(512) \\
80-2,000 \\
(906)\end{array}$ & $\begin{array}{l}223-1,728 \\
(655) \\
70-1,500 \\
(466) \\
18-567 \\
(187) \\
33-883 \\
(330) \\
40-1,031 \\
(307)\end{array}$ & $\begin{array}{l}0-9 \\
0-72 \\
0-15 \\
0-13 \\
0-9\end{array}$ & $\begin{array}{l}70-450 \\
(204) \\
132-560 \\
(365) \\
45-4,400 \\
(327) \\
50-500 \\
(219) \\
80-450 \\
(219)\end{array}$ \\
\hline
\end{tabular}

Figures in brackets are the means.

*Swithinbank et al. (1953). J. Path. Bact.. 65, 565.

†Smith et al. (1957). J. Neurol. Neurosurg. Psychiat., 20, 1. 
considerably the reported pattern of cellular response.

In the present series the rise in protein was often more conspicuous than in the psychotic group; more so in fact than in the Oxford series (Table III). Substantially raised cerebrospinal fluid protein levels for more than 10 days are, however, shown for psychotic patients in Fig. 1 and Fig. 2 of Swithinbank et al. (1953).

The significant difference in the psychotics is that they have a very much higher initial cell count and percentage of polymorphonuclear cells. It is possible that this difference is the result of diminished tuberculin sensitivity in the theca of patients with chronic neurological disease possibly analogous with that seen in the skin in acute infectious illnesses, Hodgkin's, and other diseases. On the other hand, the possibility that the abnormality is in the psychotic group cannot be ignored.

The present series is too small, uncontrolled, and too recently treated to permit any conclusions to be drawn as to the therapeutic value of intrathecal P.P.D. The acute reaction may be severe, with a temporary exacerbation of existing neurological signs. Loss of sphincter control is especially common and in the patients with multiple sclerosis may persist for several weeks. The severity of the reaction in some of the patients with Parkinsonism was sufficient to discourage further exploration of this method of treatment.
The final therapeutic assessment of intrathecal P.P.D. in multiple sclerosis must await the results of a controlled clinical trial. The present findings do not in any way nullify the suggestion that this treatment may be of benefit. It is clear, however, that the lack of specificity of the response in multiple sclerosis is a disappointing finding.

\section{Summary}

The response in the cerebrospinal fluid to the intrathecal injection of tuberculin has been studied in multiple sclerosis, motor neurone disease, Parkinsonism, and Huntington's chorea without dementia.

Two types of response are described, the first being a slow rise in the levels of cells and protein, and the second an abrupt rise within 24 to 48 hours followed by a second rise or plateau at three to eight days.

Both types of response are encountered in each of the four neurological diseases described. The response to intrathecal tuberculin in multiple sclerosis is not therefore specific to this disease.

\section{REFERENCES}

O'Grady, F. (1956). Brit. J. Tuberc. Dis. Chest, 50, 159.

(1957). Ibid., 51, 74.

Smith, H. V., Espir, M. L. E., Whitty, C. W. M., and Russell, W. R (1957). J. Neurol. Neurosurg. Psychiat., 20, 1 . Vollum, R. L., Taylor, L. M., and Taylor, K. B. (1956). Tubercle (Lond.), 37, 301 .

Swithinbank, J., Smith, H. V., and Vollum, R. L. (1953). J. Path. Bact., 65, 565. 